\title{
The Commentary of City Promotional Films Based on Transitivity Theory: A Case Study of Xi'an and San Francisco
}

\author{
Yihan Weng ${ }^{1}$ \\ ${ }^{1}$ School of Foreign Languages, China Three Gorges University, China \\ Correspondence: Yihan Weng, School of Foreign Languages, China Three Gorges University, Yichang, 443000, \\ China. E-mail: yihanweng0520@163.com
}

Received: October 15, 2021

Accepted: December 5, $2021 \quad$ Online Published: January 7, 2022

doi:10.5539/ells.v12n1p42

URL: https://doi.org/10.5539/ells.v12n1p42

\begin{abstract}
Based on Halliday's theory of ideational function, this paper selects the commentary of city promotional films of Xi'an and San Francisco and analyzes them from the perspective of the transitivity system. The main purpose of this paper is to analyze the language skills of the two commentaries and to provide ideas and methods for the audience to understand such explanatory texts. This paper focuses on the following two questions: 1) How do the six processes of the transitivity system distribute in the two commentaries? 2) What are the specific functions of the six processes in the two commentaries? The results show that 1) there are two kinds of processes frequently used in explanatory texts, namely material process and relational process; 2) the frequency of mental, verbal and existential processes is relatively low; 3) behavioral process has no occurrence. The reason may be that although the textual structure and description focus of the two commentaries are different, they both belong to the applied style of oral explanation, so that they share the same social functions of shaping the city image, highlighting the city connotation and managing the city brand.
\end{abstract}

Keywords: city image, city promotional films, commentary, transitivity theory

\section{Introduction}

The study of city image can be traced back to the famous American architect Kevin Lynch, who first put forward the concept of "the image of city". From the perspective of urban planning, he discusses the importance of urban landscape by integrating architecture, sociology, psychology and other disciplines (Liu, 2019). City image generally refers to the comprehensive impression and the overall cultural perception given to people by a city. It is a symbolic explanation of the cohesion of history and culture, a cultural characteristic formed by the integration of various elements of a city, and a combination of city traditions, existing materials and modern civilization (Zhang, 2002). According to Jiang and Ye (2018), from the perspective of rhetoric, the publicity of city image is essentially a process of "making impressions" in the mind of the audience so that the key to successful city image publicity is to increase the audienc's emotional identity. Therefore, producing and promoting a city image promotional film with brand narrative consciousness can not only make the city get more development opportunities, but also enhance its cultural soft power (Li \& Chen, 2021).

With a civilization of more than 5000 years, Xi' an ranks among the four ancient capitals in China, it is one of the birthplaces of the Chinese civilization and the starting point of the Silk Road. At the same time, Xi'an is also a central city in western China, and an important scientific research, education and industrial base. San Francisco, a port city on the Pacific coast, is a world-famous tourist attraction and the fourth most populous city in California. Due to its proximity to Silicon Valley, San Francisco has become one of the world's important bases for technological research and development and the financial center on the West Coast of the United States. In view of the fact that Xi' an and San Francisco are both metropolitan cities and have certain homogeneity in terms of transportation, tourism, education and scientific research, it is feasible for this paper to take these two cities as the objects of parallel analysis.

This paper selects two promotional films about Xi'an and San Francisco to analyze the transitivity system of the two commentaries within the framework of Systemic Functional Linguistics. This paper intends to reveal the different cultures, spirits and temperaments of Xi'an and San Francisco as well as China and America by analyzing the transitivity characteristics of the commentary, in order to provide insights for future city propaganda-oriented explanatory text analysis. 


\section{Data Collection}

The corpus in this paper is selected from the bilingual commentary of two city promotional films. The video about Xi' an was released in November 2017, with the title of Image Promo of Xi'an City in English (hereinafter referred to as text F1). Another video about San Francisco was released in March 2019 on www.nationalgeographic.com, with the title of Discover the allure of San Francisco in this video (hereinafter referred to as text F2). In this paper, only the English version of the two commentaries will be used for analysis.

The promotional film of Xi' an lasts 8 minutes and 37 seconds, with a total of 528 valid characters. It introduces Xi'an, a world-famous historical city, from five aspects: history, humanity, nature, life and development. The promotional film of San Francisco lasts for 3 minutes and 33 seconds, with a total of 482 valid characters. It focuses on the natural beauty of San Francisco with geographical orientation as the main line, supplemented by key words such as art, flavor, history and innovation, showing the unique charm of the city in an all-round and multi-level way.

The findings and discussion of this paper are based on the comprehensive situation after two manual comparison analyses as the data source, and all the data have been tested twice. The findings and discussion of this paper takes the comprehensive data after comparing the two-time results of manual identification as the analysis source. All the data have been tested twice so that it has certain accuracy and reliability.

\section{Analytical Framework}

Halliday argues that the transitivity system constructs our experience of the world as types of processes that can be controlled (Halliday, 2000), whose function is to divide what people see, hear and do in the real world into several kinds of processes, that is, to categorize experience through grammar, and to indicate the participants and circumstantial elements related to each process (Hu et al., 2005). Halliday distinguishes six types of processes, namely material process, mental process, relational process, verbal process, behavioral process, and existential process. These processes are in fact the generalization or classification of the ways in which clauses express the conceptual meaning (Zhang \& Zhang, 2012). The same event may be expressed in different linguistic processes, and the same linguistic process may be expressed in different ways. The choice and use of transitivity system is directly related to the degree and way of understanding of both objective and subjective world (Zhu, 2005). The purpose of transitivity analysis is to explore which social, cultural, ideological, and political factors determine the type of process (verb) in a particular category of text (Mayr, 2008). In view of this, we believe that the system of transitivity provides new methods for text analysis and helps people to probe the hidden information through the surface form of language.

\section{Results and Discussion}

As can be seen from Table 1, the two texts share similar system of transitivity. Material process is used most frequently, followed by relational process. Mental process, verbal process and existential process are used less frequently, and behavioral process has no occurrence. In this section, the five kinds of processes in texts F1 and F2 will be analyzed in detail.

Table 1. Six processes in text F1 \& F2

\begin{tabular}{lllll}
\hline & Text F1 (Xi'an) & & Text F2 (San Francisco) \\
\hline Process & $\mathrm{N}=46$ & $\mathrm{P}=100$ & $\mathrm{~N}=37$ & $\mathrm{P}=100$ \\
Material & 27 & 58.69 & 24 & 64.86 \\
Mental & 3 & 6.52 & 2 & 5.41 \\
Relational & 12 & 26.09 & 10 & 27.03 \\
Behavioral & 0 & 0 & 0 & 0 \\
Verbal & 2 & 4.35 & 1 & 2.70 \\
Existential & 2 & 4.35 & 0 & 0 \\
\hline
\end{tabular}

Note. $\mathrm{N}=$ number, $\mathrm{P}=$ percentage.

\subsection{Material Process}

Material process is the construction of the external world and what people do, or a series of events happened in the objective world. It is the most frequently used process in both F1 and F2 texts, which completely meets the needs of language field and reflects that commentary belongs to the applied style of oral explanation. It is worth noting that text F2 takes the natural and cultural landscape of San Francisco as the main illustrative object, so that all the actors in the material process are concrete nouns or personal pronouns. For example (the bold italics 
represent material process verbs and the underlined parts represent actors):

(1) The Gold Rush, immigration, beatniks, hippies, the LGBTQ community, and the tech industry have all fueled San Francisco's enduring influence on American culture.

(2) You can also explore the modern ruins of the Sutro Baths.

Sentence (1) is at the end of the first paragraph in the text F2, which is a paragraph full of general statements. There are six noun phrases serving as both subject and actor in sentence (1). The original meaning of the predicate verb "fuel" is to supply something with material that can be burnt produce heat or power, or to put petrol/gas into a vehicle. In this sentence, the verb "fuel" can be extended to the meaning of promotion. It shows that the city of San Francisco has always attracted numerous pioneers and anti-mainstream groups, who are full of adventure spirit, active in thinking, dare to break through the shackles of tradition and pursue the liberation of individuality (Luo, 2012). This is in line with the liberal and democratic governance concept of the United States. In sentence (2), the second personal pronoun is used as both subject and actor, aiming to strengthen the sense of interaction between the promotional film and the audience. Through the certain use of subject in the commentary, which is the medium of sound language, the promotional film can draw a psychological distance with the audience. What's more, "Explore"and "Sutro Baths" combine to form a verb-object collocation in this sentence. The Sutro Baths was a large sea-bathing resort in San Francisco, it was destroyed by the fire in 1966 and left nothing but piles of debris. However, due to its proximity to cliffs, the ruins has become a hot scenic spot among adventure seekers and photographers. Soon the Sutro Baths became one of the most popular places to visit in San Francisco because of its historical and aesthetic value. This is sort of a demonstration to the willingness of the people of San Francisco to explore and experiment with alternative ways of life, and further to shape an adventurous image of San Francisco.

Text F1 introduces Xi'an from five aspects, namely history, humanity, nature, life and development. Therefore, the material process in the text F1 can not only express actual actions, but also reflect abstract behaviors or events. Table 2 shows the classification statistics of the actors in text F1.

Table 2. Actors in text F1 (Xi'an)

\begin{tabular}{llll}
\hline Actor & & Number & Percentage \\
\hline Concrete & this wonderland / the Belt and Road Initiative / China Railway Express to Europe / Xi' an... & 12 & $54.55 \%$ \\
Abstract & $\begin{array}{l}\text { the hustle and bustle / history and modernity / the most incredible sound of faith / that } \\
\text { strength / Nature's rhythm... }\end{array}$ & 8 & $36.36 \%$ \\
Pronoun & they / you & 2 & $9.09 \%$ \\
\hline
\end{tabular}

Compared with text F2, there is an additional type of actors in text F1, namely abstract nouns. Among all the actors, concrete nouns account for the largest proportion, followed by abstract nouns, and personal pronouns only appear twice. Throughout the whole text, the content covers aspects of history, humanity, nature, life and development, which belongs to the comprehensive explanatory text. Concrete nouns are used most frequently in the part of development, while abstract nouns are concentrated in the part of history, humanities and nature. For example (the bold italics represent material process verbs and the underlined parts represent actors):

(3) China Railway Express to Europe, along the Silk Road Economic Belt, links Europe and Asia continents.

(4) Xi' an International Trade \& Logistics Park and the China (Shanxi) Pilot Free Trade Zone demonstrate the growing prosperity here.

(5) In a unique way history and modernity meet.

(6) From the depth of the soul, the most incredible sound of faith, featuring the mysterious flavor of the East, captivates you.

(7) Nature's rhythm nurtures every passerby to be who they will be.

The part of development in text F1 demonstrates that Xi'an, as an international comprehensive transportation hub and an important industrial base in China, plays an important role in promoting the regional connection of Eurasia and leading the economic development of Northwest China. Therefore, the subjects and actors in these sentences are noun phrases representing entities, emphasizing that Xi'an's prosperity in various fields. This part of the text belongs to the plain commentary, and the characters are extremely illustrative and concise, as shown in sentence (3) and (4). While the parts of history, humanities and nature belong to the literary type of commentary and the main function is to explain history, express emotion and foil artistic conception in the 
audio-visual space compatible with sound and image. Therefore, the subjects and actors in these sentences are noun phrases representing the abstract concepts with the intention to deepen the image of Xi'an as a famous historical and cultural city in the audience's minds, as shown in sentence (5), (6) and (7).

\subsection{Relational Process}

Systemic Functional Grammar holds that relational process is the most direct way to show the relationship between things and the speaker's attitudes as well as to make evaluation and judgment ( $\mathrm{Wu} \& \mathrm{Hu}, 2014$ ). Relational clauses serve to characterize and to identify. The English system operates with three main types of relation, namely intensive, possessive and circumstantial; and each of these comes in two distinct modes of being, which are attributive and identifying ( $\mathrm{Li} \& \mathrm{Li}, 2019)$. Relational processes account for $26.09 \%$ in text $\mathrm{F} 1$ and $26.32 \%$ in text F2. As can be seen from Table 3, there are most intensive relational processes in the two texts, and all of them belong to the identifying type. This process refers to that one entity determines the specific identity of another entity.

Table 3. Relational process in text F1 \& F2

\begin{tabular}{llllll}
\hline Text F1 (Xi'an) & & \multicolumn{5}{l}{ Text F2 (San Francisco) } \\
\hline $\mathrm{N}=12$ & Attributive & Identifying & $\mathrm{N}=9$ & Attributive & Identifying \\
\hline Intensive & 0 & 7 & Intensive & 0 & 4 \\
Circumstantial & 1 & 0 & Circumstantial & 2 & 0 \\
Possessive & 2 & 2 & Possessive & 3 & 0 \\
\hline
\end{tabular}

Note. $\mathrm{N}=$ number.

For example (the bold italics represent the intensive relational process and the underlined parts represent the identified):

(8) It is universally rare that a city can be home to both incredible historic heritage and modern civilization. (F1)

(9) San Francisco is a rush. (F2)

Sentence (8) and (9) share several features. They are both in the beginning of the texts, the identifieds are both the cities, namely Xi' an and San Francisco, and the verbs are both different forms of "be". In sentence (8), "it" serves as the formal subject. The application of this emphatic pattern aims to emphasize that Xi'an is one of the few cities where history and modernity have been perfectly integrated. It helps the audience to grasp the overall impression of Xi'an. Sentence (9) is a typical simple sentence with subject-verb-object structure. However, the usage of its identifier, namely the object, is of great significance here. As a noun, "rush" has several meanings such as hurry, busy situation, a sudden strong emotion, etc. Therefore, using this word can make the audience instantly perceive the characteristics of San Francisco, which are the fast pace of life and the diversity of culture.

According to Table 3, there are least circumstantial relational processes in the two texts, and all of them belong to the attributive type. This process refers to the relationship between an entity and the environmental factors. For example (the bold italics represents the circumstantial relational process, the bullet points represent the carrier, and the underlined parts represent the attribute):

(10) ... and even food is tastefully beyond the grasp of your taste buds. (F1)

(11) It.. all packed into a seven-by-seven-mile square, between the Pacific Ocean and the San Francisco Bay. (F2)

Sentence (10) is in the part of life of text F1, and the attribute is composed of a prepositional phrase. Xi'an has long been known for its cooked wheaten food and the wide variety of snacks. This sentence points out the unspeakable deliciousness of the food in Xi'an and highlights the city's unique charm, which is full of human touch and lively atmosphere. The subject and carrier in sentence (11) is a third person pronoun, which refers to the city of San Francisco. In this sentence, the verb is in the passive form and the attribute is made up of two parallel prepositional phrases. Such a sentence structure clearly illustrates the geographical location of San Francisco, and plays a role of connecting with the video images and deepening the audience's perception.

As is shown in Table 3, there are four possessive relational processes in text F1, among which the attributive type and the identifying type are each half. In text F2, there are three possessive relational processes, all of which belong to the attributive type. As to the attributive category, the possessive process refers to the relationship in which an entity is owned by someone. While in the identifying category, the concept of possession can be represented by the participants. For example (the bold italics represents the possessive relational process, the 
bullet points represent the carrier, and the underlined parts represent the attribute):

(12) Qinling Mountains dotted with historic relics houses gorgeous natural scenes. (F1)

(13) $20 \%$ larger than New York's Central Park, it covers a thousand square acres in a near perfect rectangle.......

(14) Behind a red-painted, time-weathered gate may lie a dusty story. (F1)

(15) Persons with higher education comprise about one-tenth of Xi' an's population. (F1)

Sentence (12) and (13) both belong to the attributive type of relational process. Sentence (12) emphasizes the beautiful natural landscape of Qinling Mountains. In sentence (13), by contrast with New York's Central Park, it highlights the huge area of the subject, namely Golden Gate Park. It can be seen that the attributive type of possessive relational processes in the two texts are mostly used to describe natural scenes or tourist attractions, with the intention of emphasizing their attributes or features. Here, sentence (12) and (13) respectively highlight the beauty of Qinling Mountains and the massiveness of Golden Gate Park. Sentence (14) and (15) both appear in text F1 and belong to the identifying type of relational process. In sentence (14), the two participants, which are "time-weathered gate" and "a dusty story", indicate the profound historical background of Xi'an. As to sentence (15), there is a typical possessive relative verb-comprise. Considering the logical connection between the two participants, this sentence demonstrates that Xi'an, an important central city in western China, has made great achievements in higher education.

\subsection{Mental Process}

Mental process is the presentation of the internal world and people's perception of the external world. A mental process involves two participants: Senser and Phenomenon. Mental processes account for $6.25 \%$ in text F1 and $5.26 \%$ in text $\mathrm{F} 2$.

Table 4. Mental process in text F1 \& F2

\begin{tabular}{lllll}
\hline Text F1 (Xi'an) & \multicolumn{3}{l}{} & \\
& Senser & Process: Mental & & $\begin{array}{l}\text { Phenomenon } \\
\text { strength }\end{array}$ \\
$(16)$ & You & feel & [feeling] & no dimension \\
$(17)$ & Time & know & $\begin{array}{l}\text { [cognition] } \\
\text { [cognition] }\end{array}$ & no borders \\
$(18)$ & Space & know & & \\
Text F2 & (San Francisco) & & & Phenomenon \\
& Senser & Process: Mental & & a movie \\
$(19)$ & You & see & [feeling] & Chinatown \\
$(20)$ & You & see & [feeling] & \\
\hline
\end{tabular}

It can be seen from Table 4 that mental process is not frequently used in the two texts, but the use of verbs and sensers in text F1 is obviously more diversified and richer than that in text F2. Sentence (16) is in the humanity part of text F1, it uses the second personal pronoun as the senser, aiming to connect the audience's internal emotional mechanism. In this case, it highlights that the abundant cultural history of Xi'an becomes local people's spiritual nourishment and empowers them in an invisible way. Sentence (17) and (18) share the same structure and the same verb for cognition, stating that the charm of Xi'an transcends the limitations of time and space and emphasizing that it is a city with a perfect blend of ancient and modern civilization. Compared with the slightly obscure description of abstract concepts in the mental process of text F1, the language of text F2 is straightforward and clear. Sentence (19) and (20) are two clauses which belong to the same main-subordinate complex sentence, with the second person pronoun and the sensory verb forming the subject-predicate structure. Here, Chinatown is introduced from the topic of movie, which demonstrates its historical and cultural significance in San Francisco and even the important contribution of the Chinese in the American history.

\subsection{Verbal Process}

Verbal process is that of exchanging information. The main participants include sayer, receiver and verbiage. Verbal processes account for $4.35 \%$ in text F1 and $2.63 \%$ in text F2. Table 5 shows the verbal processes involved in the two texts.

Table 5. Verbal process in text F1 \& F2

\begin{tabular}{|c|c|c|c|}
\hline \multirow{2}{*}{$\begin{array}{r}\text { Text F1 (Xi'an) } \\
\text { Sayer }\end{array}$} & & & \\
\hline & Process: Verbal & Receiver & Verbiage \\
\hline
\end{tabular}




\begin{tabular}{|c|c|c|c|c|}
\hline (21) & Old buildings and steles & tell & - & secrets \\
\hline (22) & Any fine words & fail to describe & - & the grandeur of scenery \\
\hline \multicolumn{5}{|c|}{ Text F2 (San Francisco) } \\
\hline (23) & $\begin{array}{l}\text { Sayer } \\
\text { The Dragon Gate }\end{array}$ & $\begin{array}{l}\text { Process: Verbal } \\
\text { tells }\end{array}$ & $\begin{array}{l}\text { Receiver } \\
\text { visitors }\end{array}$ & $\begin{array}{l}\text { Verbiage } \\
\text { they're entering America's oldest Chinatown }\end{array}$ \\
\hline
\end{tabular}

In sentence (21), the verbal process is used to show that people can feel that Xi'an is rich in history from the architectures in this city. The wording is full of literary beauty. This way of expression is also in line with the language characteristics of laying emphasis on artistic conception and connotation in Chinese. There is a verb infinitive in sentence (22), which is made up of a verb expressing negative meaning and a verb representing the verbal process. It is used to serve as a foil to the unspeakable beauty of Xi'an's natural scenery; the tone is euphemistic and implicit, however. As a result, the static text and dynamic images can be more easily accepted and perceived by the audience. Sentence (23) and (21) share the same verb, but the former one baldly illustrates that the the landmark of the Dragon Gate serves as a geographical indicator for Chinatown. Compared with sentence (21), sentence (23) is more descriptive.

\subsection{Existential Process}

Existential process represents that something exists or happens, which can be used to express the objectivity of things. There must be one participant in the existential process, namely existent. In this section, existential process only exists in text F1, accounting for $4.35 \%$.

Table 6. Existential process in text F1 (Xi'an)

\begin{tabular}{|c|c|c|c|}
\hline \multicolumn{4}{|c|}{ Text F1 (Xi'an) } \\
\hline (24) & $\begin{array}{l}\text { Existent } \\
\text { splendid civilization }\end{array}$ & $\begin{array}{l}\text { Process: Existential } \\
\text { is scattered }\end{array}$ & $\begin{array}{l}\text { Circumstance } \\
\text { at every nook and corner of this city }\end{array}$ \\
\hline (25) & $\begin{array}{l}\text { The largest Asian Aviation City and China's } \\
\text { Aerospace City }\end{array}$ & are situated & here \\
\hline
\end{tabular}

As can be seen from Table 6, the predicate verb in sentence (24) is in the passive form, emphasizing that Xi' an is the birthplace of ancient Chinese civilization in Qin, Han and Tang dynasties. From the Chinese-style eaves on the street buildings to the quaint lamp posts standing on sides of the road, the marks of the Han-Tang culture can be seen everywhere in Xi'an. Sentence (25) focuses on the modernization process of Xi'an, which objectively shows that the aviation industry in this city has maintained good momentum of development, and further establishes Xi'an's position as an important industrial base and the international transport corridor in China.

\section{Conclusion}

The transitivity analytical results show that the two texts contain similar processes. Firstly, material process is used most frequently. It is used to comprehensively describe the history, humanity, nature, life and development of Xi'an in text F1, while introduce the natural and cultural landscape of San Francisco in text F2. Secondly, relational process is used to determine the two cities' distinctive features. Thirdly, mental process reflects the importance of history in shaping a city's spiritual culture. What's more, verbal process highlights the distinct linguistic features of the two texts. Finally, existential process reflects that Xi'an is a city with a perfect blend of ancient and modern civilization. In short, the commentary of the two cities have their own characteristics, which are comprehensive in content and profound in connotation, showing the quaint and modern features of Xi'an, and the innovative and explorative features of San Francisco. To be specific, they both narrate tales of the city according to their own city orientation and characteristic resources, which not only helps find a path suitable for their own development, but also interpret the spiritual style of the city.

\section{References}

Halliday, M. A. K. (2000). An introduction to functional grammar (2nd ed.). Beijing: Foreign Language Teaching and Research Press.

Hu, Z. L., Zhu, Y. S., Zhang, D. L., \& Li, Z. Z. (2005). An Introduction to Systemic Functional Linguistics. Beijing: Peking University Press.

Jiang, X., \& Ye, Y. (2018). A Study on External Communication Strategy of City Image Promotional Films. Youth Journalist, 20, 27-28. 
Li, J., \& Li, F. J. (2019). A Case Study of Transitivity Analysis of Trump's Winning Speech Based on Systematic Functional Grammar. International Journal of Language and Linguistics, 7(4), 150-157. https://doi.org/10.11648/j.ij11.20190704.12

Li, M., \& Chen, S. H. (2021). A Study on the Brand Narrative Consciousness of City Image Promotional Films. Contemporary Communications, 6, 97-99.

Liu, G. Z. (2019). A Study on the Dissemination of City Image from the Perspective of Cultural Semiotics. Youth Journalist, 11, 77-79.

Luo, L. (2012). A Cultural Study of San Francisco. World Culture, 8, 42-45.

Mayr, A. (2008). Language and Power: An Introduction to Institutional Discourse. London: Continuum International Publishing Group.

Wu, Q. L., \& Hu, X. Q. (2014). Analysis on President Xi Jinping's 2014 New Year's Speech from the Perspective of Transitivity. China Three Gorges Tribune, 3, 102-105.

Zhang, H. Y. (2002). City Image and City Cultural Capital. Nanjing: Southeast University Press.

Zhang, S. B., \& Zhang, X. X. (2012). A Transitivity Approach to English Neutral News. Journal of Hebei University (Philosophy and Social Science), 2, 148-151.

Zhu, Y. S. (2005). A Dynamic Study on Context. Beijing: Peking University Press.

\section{Copyrights}

Copyright for this article is retained by the author, with first publication rights granted to the journal.

This is an open-access article distributed under the terms and conditions of the Creative Commons Attribution license (http://creativecommons.org/licenses/by/4.0/). 